\title{
The role of extended scope physiotherapists in managing patients with inflammatory arthropathies: a systematic review
}

This article was published in the following Dove Press journal:

Open Access Rheumatology: Research and Reviews

30 May 2012

Number of times this article has been viewed

\author{
Jessica Stanhope' \\ Kate Beaton' \\ Karen Grimmer-Somers' \\ Joanne Morris ${ }^{2}$ \\ 'International Centre for Allied \\ Health Evidence (iCAHE), University \\ of South Australia, Adelaide, South \\ Australia; ${ }^{2} \mathrm{ACT}$ Government Health \\ Directorate, Canberra, Australian \\ Capital Territory, Australia
}

Objectives: To review the literature to identify whether, and how, physiotherapists working in extended scope of practice (ESP) engage with patients with inflammatory arthropathies. Measures of effectiveness of ESP were particularly sought.

Methods: A comprehensive library database search was conducted to identify English language studies published in full text in peer-reviewed journals during the years 2002-2012. Studies were allocated into the National Health and Medical Research Council hierarchy of evidence, but were not critically appraised. Data was extracted on conditions treated, ESP roles and responsibilities, and effectiveness. Data was analyzed and reported descriptively.

Results: We identified 123 studies, and included four. All were low hierarchy (highest being one level III_2 study). Commonly reported conditions were rheumatoid arthritis and ankylosing spondylitis. Information was provided on activities of role extension, such as triaging patients, monitoring and recommending changes to medications, referring to other health and medical professionals, and ordering and interpreting imaging. There was blurring between ESP and non-ESP roles. No study reported measures of effectiveness.

Conclusion: There are descriptors of ESP physiotherapy activities, but no evidence of effectiveness of ESP physiotherapy in managing patients with inflammatory arthropathies.

Keywords: ESP, extended scope, rheumatoid arthritis, ankylosing spondylitis, inflammatory arthropathy, physiotherapy

\section{Background}

We conducted a review of the literature to establish whether and how physiotherapists working in extended scope of practice (ESP) roles manage patients with inflammatory arthropathies. Working in ESP involves performing tasks outside the usual scope of physiotherapy practice, including injecting, requesting and interpreting imaging and other investigations, prescribing, referring patients to medical providers, and listing patients for surgery. ${ }^{1,2}$

A review of the roles undertaken by physiotherapists working in ESP in any field was conducted by Lowe and Prior in $2008 .^{3}$ At this time, only limited data were reported regarding the role of ESP physiotherapists in rheumatology.

Recently, we published a systematic review ${ }^{4}$ of literature describing the roles and effectiveness of ESP physiotherapists managing orthopedic outpatients. This review built upon the orthopedic component of the Lowe and Prior $^{3}$ review, identifying six additional studies. The new studies were of a lower level of evidence, but suggested that the role of ESP physiotherapists in managing orthopedic outpatients may lead to improved efficiency, in terms of patient management pathways. Our review also
Correspondence: Karen Grimmer-Somers International Centre for Allied Health Evidence, University of South Australia, Adelaide, South Australia, Australia Tel +61883022769

Fax +6I 883022853

Email karen.grimmer-somers@unisa. edu.au
Open Access Rheumatology: Research and Reviews 2012:4 49-55

(C) 2012 Stanhope et al, publisher and licensee Dove Medical Press Ltd. This is an Open Access article which permits unrestricted noncommercial use, provided the original work is properly cited.
Dovepress 
suggested that ESP physiotherapists may achieve outcomes equivalent to medical practitioners, in terms of diagnosing orthopedic conditions.

Inflammatory arthropathies refer to the presence of true inflammation in the joint tissues, particularly the synovium. ${ }^{5}$ This should not be confused with osteoarthritis which is a degenerative condition of the joints. ${ }^{5}$ The term inflammatory arthropathies includes septic arthritis, gout, rheumatoid arthritis, ankylosing spondylitis, reactive arthritis, and psoriatic arthritis. ${ }^{5}$ The primary features of these conditions are dysfunction, joint pain, and joint destruction. ${ }^{5}$ Management aims of these conditions focus on symptom relief, managing the autoimmune or inflammatory processes underlying the conditions, or surgery to correct deformities or to repair joints. ${ }^{5}$

This review explores whether there is new literature regarding the roles of ESP physiotherapists in managing patients with inflammatory arthropathies, the conditions they treat, the environments in which they work and with whom they work, and what outcomes are achieved from working in these roles.

\section{Methods}

\section{Research questions}

The review research questions were:

1. What peer-reviewed literature has been published in the last 10 years describing the roles of ESP physiotherapists in managing patients with inflammatory arthropathies?

2. Where do these ESP physiotherapists work, how do they work, and with whom do they work?

3. What benefits are there for patients with inflammatory arthropathies in being managed by an ESP physiotherapist?

4. Are there benefits for the health system, or other health providers, of having physiotherapists working in ESP roles for patients with inflammatory arthropathies?

\section{Search criteria}

An electronic database search was conducted in January 2012 to identify studies published in English in full text peer-reviewed journals in the past 10 years (2002-2012), regarding ESP physiotherapists management of patients with inflammatory arthropathies. This was conducted by one author with independent advice provided by a second author. Studies which investigated the management of arthritis, without stating whether this was of an inflammatory nature, were excluded. Lowe and Prior ${ }^{3}$ found in 2008 that ESP in any area of physiotherapy practice was a relatively new phenomenon, and that the bulk of the literature had been reported since 2000, with no peer-reviewed studies published at this time. Our review built on this finding, by limiting the search timeframe to 10 years.

The interventions administered by the ESP physiotherapist had to be specifically defined as ESP roles, or interventions relevant to Australian conditions. ESP in Australia is conceptualized as part of a skills escalator program, which describes a continuum of activities undertaken by allied health assistants, in-scope, advanced and then extended scope allied health practitioners. ${ }^{6}$ Thus the definition provided by the Australian Physiotherapy Association was used, for extension of scope of practice:

A role that is outside the currently recognised scope of practice and requires legislative change. Extended scope of practice requires some method of credentialing following additional training, competency development and significant clinical experience. Examples include prescribing, injecting and surgery. This role describes the breadth of practice. ${ }^{1}$

However, we were cognizant of the difficulties that we may encounter in this review, in terms of capturing activities that were truly an extension of physiotherapy scope of practice in Australia. Difficulties included the way physiotherapy practices operated in the countries in which the included research had been conducted. McPherson et $\mathrm{al}^{7}$ and Sibbald et $\mathrm{al}^{8}$ highlighted the importance of understanding country-specific activities when considering role extension, for instance impact of historical practice, legislative constraints, local interprofessional relationships, environmental constraints, and training. Thus in this review, we were interested in any activity which was described in the included paper as outside scope of practice in that country.

Studies of any hierarchy, reporting any information on ESP management of patients with inflammatory arthropathies were eligible for inclusion.

\section{Search terms}

The search terms reported in Table 1 were searched in all text/fields in each database, with results limited to those published 2002-2012.

\section{Databases searched}

Cochrane Library; EBSCOhost (Academic Search Premier, AgeLine, CINAHL, E-Journals, Health Business Elite, Health Source: Consumer Edition, Health Source: Nursing/Academic 
Table I Search terms

\begin{tabular}{|c|c|c|c|c|}
\hline Physiotherapy terms & & ESP terms & & Inflammatory arthropathy terms \\
\hline physiotherap* & & "extended scope" & & rheumat* OR "inflammatory arthr*” OR "rheumatoid arthr" OR \\
\hline \multirow[t]{5}{*}{ OR "physical therap*” } & AND & OR "extended practice" & AND & “ankylosing spondylitis” OR “reactive arthr*” OR Reiter's OR \\
\hline & & OR ESP & & "psoriatic arthr*" OR "arthritis psoria*" OR "arthropathic psoriasis" OR \\
\hline & & & & "juvenile idiopathic arthr*” OR "juvenile chronic arthr*” OR gout OR \\
\hline & & & & podagra OR “septic arthr*” OR “infectious arthr*” OR \\
\hline & & & & "suppurative arthr*” OR “pyogenic arthr*” \\
\hline
\end{tabular}

Edition, SPORTDiscus); Ovid (AMED, Embase, Medline, Nursing Database); Scopus; and PubMed were searched.

\section{Level of evidence}

The study design was determined, and the study assigned a hierarchy of evidence according to the National Health and Medical Research Council (NHMRC) Level of Evidence. ${ }^{9}$

\section{Critical appraisal}

Only studies classified as Levels I, II or III_1 were intended for critical appraisal, as the inherent methodological bias in studies of lower hierarchy designs was likely to attenuate the believability of findings. The relevant Critical Appraisal Skills Program tool ${ }^{10}$ would be applied if critical appraisal was indicated.

\section{Data extraction}

The following data were manually extracted into a purposebuilt Excel spreadsheet (Microsoft, Redmond, WA), with the following headings: the year of publication, country, type of research, the definition reported for ESP physiotherapists, the clinical environment, other staff they work with, ESP tasks, specific conditions managed, and/or any potential benefits of implementing an ESP physiotherapy role in terms of health, process and/or cost measures. Data were extracted by one author with independent advice from a second author regarding the type of data extracted.

\section{Results}

We identified 123 potentially relevant studies. Ten were duplicates (subsequently removed), whilst a further 102 studies were removed after screening the title and abstract. Of the eleven remaining studies, six were excluded as inflammatory arthropathies were not managed, and one was excluded as it did not report on ESP physiotherapists. Four studies were therefore included in this review. The Preferred Reporting Items for Systematic Reviews and Meta-Analyses (PRISMA) flow diagram ${ }^{11}$ is reported in Figure 1.

\section{Year, country, research type, and NHMRC level of evidence}

The included papers had been published in two countries (Canada and The Netherlands) (see Table 2). All included studies were published from 2008 onwards. A variety of study designs were represented, although they were generally of low hierarchy as reported in Table 2.

\section{Critical appraisal}

None of the studies met the inclusion criteria necessary for critical appraisal.

\section{Data extraction} Definitions for ESP physiotherapy

MacKay et $\mathrm{al}^{15}$ noted the variation of terms used to describe extended practice roles, and consequently referred to these as expanded roles of practice (expanded role providers), defined as "those requiring advanced clinical skills and knowledge, which often include performing additional acts such as ordering diagnostic tests or prescribing medications".

Conversely Li et al ${ }^{12}$ applied the Chartered Society of Physiotherapy $(\mathrm{UK})^{2}$ definition of ESP physiotherapists, physiotherapists "who are working beyond the recognized scope of practice of the profession of interest in innovative or non-traditional roles".

\section{Clinical environment in which they worked}

According to MacKay et al the clinical environments in which ESP physiotherapists (or expanded role providers) work included outpatient hospital settings, triaging roles, and as part of clinical assessment and treatment services (CATS). ${ }^{15}$

\section{Multidisciplinary approach}

MacKay et al also noted that ESP physiotherapists were described as working with occupational therapists, podiatrists, other physiotherapists (including ESP and consultant physiotherapists), primary physicians or general practitioners with 




Figure I PRISMA flow diagram.

Copyright (C) 2009, Public Library of Science.

Adapted with permission from Moher D, Liberati A, Tetzlaff J, Altman DG, PRISMA Group. Preferred reporting items for systematic reviews and meta-analyses: the PRISMA statement. PLoS Med. 2009;6(7):el000097."'

special interests in rheumatology, and medical specialists such as orthopedic surgeons and rheumatologists. ${ }^{15}$

\section{Types of inflammatory arthropathies managed}

ESP physiotherapists have been reported to manage patients with rheumatoid arthritis, ${ }^{12,14,15}$ ankylosing spondylitis, ${ }^{15}$ and psoriatic arthritis. ${ }^{15}$ Some patients may also be undiagnosed when they commence management with the ESP physiotherapist. ${ }^{12,14}$ Lineker et $\mathrm{al}^{13}$ compared the diagnoses of the patients who consulted ESP physiotherapists with those from experienced physiotherapists, as reported in Table 3.

Table 2 Year, country, research type, and NHMRC level of evidence

\begin{tabular}{lclll}
\hline Study & Year & Country & Study designs & $\begin{array}{l}\text { Level of } \\
\text { evidence }\end{array}$ \\
\hline${\text { Li et } \text { al }^{12}}^{2010}$ & $\begin{array}{l}\text { Canada and } \\
\text { Netherlands } \\
\text { Lineker et al }\end{array}$ & Canada & $\begin{array}{l}\text { Retrospective } \\
\text { audit }\end{array}$ & III_2 \\
Lundon et al $^{14}$ & 2011 & $\begin{array}{l}\text { Canada } \\
\text { Canada }\end{array}$ & $\begin{array}{l}\text { Pre-post } \\
\text { Qualitative }\end{array}$ & IV \\
\hline MacKay et al ${ }^{15}$ & 2008 & Canal \\
\hline
\end{tabular}

Abbreviation: NHMRC, National Health and Medical Research Council.

\section{ESP physiotherapy tasks}

Lundon et $\mathrm{al}^{14}$ presented a training program for ESP physiotherapists and occupational therapists that was specifically aimed at the management of patients with rheumatoid arthritis and osteoarthritis. The ESP tasks developed in this course included ordering and interpreting investigations (diagnostic imaging and laboratory tests), triaging patients, monitoring medications, and managing patients with selected forms

Table 3 Percentage of patients seen with each condition by the extended role practitioners and experienced physiotherapists

\begin{tabular}{lll}
\hline Primary diagnosis & $\begin{array}{l}\text { Extended role } \\
\text { practitioner } \\
\mathbf{n}(\%)\end{array}$ & $\begin{array}{l}\text { Experienced } \\
\text { physiotherapists } \\
\mathbf{n}(\%)\end{array}$ \\
\hline Rheumatoid arthritis & $13(44.8)$ & $22(75.9)$ \\
Seronegative arthritis & $9(31.0)$ & $4(13.8)$ \\
Undifferentiated arthritis & $3(10.3)$ & $0(0)$ \\
Other & $4(13.8)$ & $3(10.3)$ \\
\hline
\end{tabular}

Note: Extended role practitioners $n=29$, experienced physiotherapists $n=29$. Copyright (C) 201 I, University of Toronto Press.

Adapted with permission from Lineker SC, Lundon K, Shupak R, Schneider R, MacKay C, Varatharasan N. Arthritis extended-role practitioners: impact on community practice (an exploratory study). Physiother Can. 201 I;63(4):434-442.13 
of arthritis independent of medical practitioners. It was not clear from this paper which of these tasks related to the management of rheumatoid arthritis, compared with osteoarthritis.

According to MacKay et $\mathrm{al}^{15}$ patients were referred to ESP physiotherapists by primary care physicians, and ESP physiotherapists referred patients to other health and medical professionals, and made recommendations regarding medications (or changes to current medications).

\section{ESP tasks being performed by non-ESP physiotherapists}

The lack of a clear definition regarding the roles and responsibilities of ESP physiotherapists in managing inflammatory arthropathies means that there are variations in the descriptions of what constitutes an extended scope task.

Li et $\mathrm{al}^{12}$ surveyed Dutch and Canadian physiotherapists who had consulted with a patient with rheumatoid arthritis within the last month. The Canadian therapists were working in orthopedics, whilst the Dutch physical therapists formed two groups; those who were members of a regional arthritis network, and those working in any area of physical therapy. These therapists did not necessarily class themselves as ESP therapists. For the purpose of this review, we extracted data only on those physiotherapists who had consulted a patient with rheumatoid arthritis within the last month. Only 5.9\% of the physiotherapists from Canada, and $1 \%$ and $0 \%$ of the physical therapists from the respective Netherlands groups, stated that they worked outside the usual scope of physiotherapy practice. However, screening patients for physicians and referring patients to other health professionals are generally considered ESP roles, yet a greater percentage of respondents reported carrying out these tasks, as reported in Table 4.

A similar situation was reported by Lineker et $a 1^{13}$ where both experienced and ESP physiotherapists reported making the following referrals: internal referrals for physiotherapy, occupational therapy, social work, home care or community care access center, rheumatology, x-rays, and laboratory work. The only referral made by ESP physiotherapists which was not made by experienced physiotherapists was to general practitioners, although this is likely to be due to the patient notes examined rather than it not being an ESP task. Both experienced physiotherapists and ESP physiotherapists provided education about medications to their patients, however, it was not reported what this entailed and cannot therefore be assumed that this inferred any ESP role. The referral tasks conducted by experienced physiotherapists appeared to be within-scope and therefore should be interpreted with caution, as this may be organization- or country-specific.

\section{Benefits of ESP physiotherapists}

There was no information about the benefits of ESP physiotherapists managing patients with inflammatory arthropathies in terms of health, cost and/or process measures. Therefore this review found no evidence, at this point in time, of the effectiveness of the role of extended scope physiotherapists for patients with inflammatory arthropathies.

\section{Discussion}

This review presents the first known synthesis of peerreviewed literature on the roles and responsibilities of physiotherapists working in extension of scope, in the management of patients with inflammatory arthropathies. All included studies were published since 2008, indicating the increased research interest in this area.

The available research literature base is scant, and of low hierarchy evidence, with the highest hierarchy study design level III_2. The most common conditions ESP physiotherapists were reported to be treating were rheumatoid arthritis and ankylosing spondylitis. No study reported on the benefits of implementing ESP physiotherapy roles for

Table 4 Self-reported roles undertaken by physiotherapists treating patients with rheumatoid arthritis in Canada and The Netherlands ${ }^{12}$

\begin{tabular}{|c|c|c|c|}
\hline \multirow[t]{2}{*}{ Role } & \multirow{2}{*}{$\begin{array}{l}\text { Canada } \\
\text { Physiotherapists working } \\
\text { in orthopedics (\%) }\end{array}$} & \multicolumn{2}{|l|}{ Netherlands } \\
\hline & & $\begin{array}{l}\text { Physical therapists working } \\
\text { in arthritis care (\%) }\end{array}$ & $\begin{array}{l}\text { Physical therapists working } \\
\text { in all areas of practice (\%) }\end{array}$ \\
\hline $\begin{array}{l}\text { Providing assessment and treatment outside } \\
\text { the scope of physiotherapy practice }\end{array}$ & 5.9 & 1.0 & 0.0 \\
\hline Screening patients for physicians & 7.4 & 19.8 & 12.2 \\
\hline Referring patients to medical professionals & 33.8 & 40.6 & 25.6 \\
\hline $\begin{array}{l}\text { Referring patients to other rheumatology } \\
\text { rehabilitation professionals }\end{array}$ & 14.7 & 18.8 & 12.2 \\
\hline
\end{tabular}

Copyright @ 2010, American Physical Therapy Association.

Adapted with permission from Li LC, Hurkmans EJ, Sayre EC, Vliet Vlieland TPM. Continuing professional development in association with increasing physical therapists' roles in arthritis management in Canada and The Netherlands. Phys Ther. 20 10;90(4):629-642.'2 
patients with inflammatory arthropathies, hence there is no evidence regarding the value of implementing such roles.

There remains no consensus regarding the definitions of ESP in this area, and there are discrepancies regarding the terminology. For instance, MacKay et $\mathrm{al}^{15}$ stated that in Canada, ESP roles are termed advanced practice, yet in Australia these roles are considered to be within-scope (although there was no supporting reference for this statement). MacKay et $\mathrm{al}^{15}$ added another term, that of "extended role practitioners". It is, therefore, not surprising that there are no clear tasks for ESP physiotherapists, or that physiotherapists who are not considered to be working in an ESP role may also be performing ESP tasks such as referring, and requesting investigations. ${ }^{12,13}$ This may relate to training, and registration and legislative differences between countries regarding tasks which are considered to be within the scope of physiotherapy.

\section{Strengths of this review}

This review used a robust systematic approach to find, classify, and consider the evidence available for this area of physiotherapy practice. Although the literature base is currently scant, this paper sets the scene for what is presently being undertaken around the world in terms of extension of scope physiotherapy practice for inflammatory arthropathies. Future reviews of the literature will be able to build on our processes and findings. This review highlights that further research is required to clarify the nature and outcome of physiotherapy practice for these diagnoses. It also highlights the importance of using standard definitions of role extension, so that comparisons can be made between countries.

\section{Limitations of this review}

This review reported on only English language literature. Literature which reported on general "arthritis" was not included in this review because of our specific interest in inflammatory joint conditions. Therefore, we may have overlooked reports of extended physiotherapy roles for inflammatory conditions which may have been included in general "arthritis" research papers.

\section{Conclusion}

Whilst ESP physiotherapists are reported to be involved in the management of patients with inflammatory arthropathies (particularly rheumatoid arthritis) in two countries (Canada and The Netherlands), there is no such evidence for other countries, or of the benefits of such roles, in terms of cost, health, and process outcomes. The benefits of ESP physiotherapists working with orthopedic outpatients identified by Stanhope et $\mathrm{al}^{4}$ including reduced patient waiting times and costs, could viably be expected in the management by ESP physiotherapists of patients with inflammatory arthropathies. There is an urgent need for higher hierarchy studies that specifically investigate the benefits to the patient and the organization and the profession of such roles. Moreover, more research is required on training for ESP physiotherapists working with patients with inflammatory arthropathies, including the credentialing and guidance required in the workplace by supervising medical professionals.

\section{Disclosure}

The authors report no conflicts of interest in this work.

\section{References}

1. Australian Physiotherapy Association. Position Statement: Scope of practice. Australian Physiotherapy Association: Victoria; 2009. Available from: http://physiotherapy.asn.au/images/Document_Library/ Position_Statements $/ 2014 \% 20$ scope $\% 20$ of $\% 20$ practice.pdf. Accessed November 21, 2011.

2. The Chartered Society of Physiotherapy. Chartered Physiotherapists Working as Extended Scope Practitioners (ESP): Guidance for Members. London, UK: The Chartered Society of Physiotherapy; 2003.

3. Lowe J, Prior M. A Systematic Review of the Literature on Extended Scope of Practice Physiotherapy. Canberra, Australia: ACT Government Health Directorate: ACT Government; 2008. Available from: http:// www.health.act.gov.au/c/health? $\mathrm{a}=$ sendfile $\& \mathrm{ft}=\mathrm{p} \&$ fid $=1301227758$ \&sid=. Accessed January 11, 2012.

4. Stanhope J, Grimmer-Somers K, Milanese S, Kumar S, Morris J. Extended scope physiotherapy roles for orthopaedic outpatients: an update systematic review of the literature. J Multidiscip Healthc. 2012; 5:37-45.

5. Hughes D. Osteoarthritis and inflammatory arthritis. Surgery. 2009; 27(2):75-79.

6. Gilmore LG, Morris JH, Murphy K, Grimmer-Somers K, Kumar S. Skills escalator in allied health: a time for reflection and refocus. Journal of Healthcare Leadership. 2011;3:53-58.

7. McPherson K, Kersten P, George S, et al. A systematic review of evidence about extended roles for allied health professionals. $J$ Health Serv Res Policy. 2006;11(4):240-247.

8. Sibbald B, Shen J, McBride A, Zafar R, Grimshaw D. Changing the skill mix in the NHS: a review commissioned by the human resource directorate of the Department of Health to support the NHS Changing Workforce Programme conducted under the Policy Research Programme project: New Ways of Working-A research facility to support HR policy making in the NHS. Manchester, UK:Manchester School of Management, UMIST; 2002.

9. National Health and Medical Research Council. NHMRC Levels of Evidence and Grades for Recommendations for Developers of Guidelines. National Health and Medical Research Council: Australian Government; 2009. Available from: http://www.nhmrc.gov.au/_files_nhmrc/file/guidelines/evidence_statement_form.pdf. Accessed January 23, 2012.

10. Solutions for Public Health. CASP Appraisal Tools: Solutions for Public Health; 2012. Available from: http://www.sph.nhs.uk/sph-files/ casp-appraisal-tools. Accessed March 4, 2012.

11. Moher D, Liberati A, Tetzlaff J, Altman DG, PRISMA Group. Preferred reporting items for systematic reviews and meta-analyses: the PRISMA statement. PLoS Med. 2009;6(7):e1000097. 
12. Li LC, Hurkmans EJ, Sayre EC, Vliet Vlieland TPM. Continuing professional development in association with increasing physical therapists' roles in arthritis management in Canada and The Netherlands. Phys Ther. 2010;90(4):629-642.

13. Lineker SC, Lundon K, Shupak R, Schneider R, MacKay C, Varatharasan N. Arthritis extended-role practitioners: impact on community practice (an exploratory study). Physiother Can. 2011;63(4):434-442.
14. Lundon K, Shupak R, Schneider R, Herold McIlroy J. Development and early evaluation of an inter-professional post-licensure education programme for extended practice roles in arthritis care. Physiother Can . 2011;63(1):94-103.

15. MacKay C, Veinot P, Badley EM. Characteristics of evolving models of care for arthritis: a key informant study. BMC Health Serv Res. 2008; $8(1): 147-157$

\section{Publish your work in this journal}

Open Access Rheumatology Research and Reviews is an international, peer-reviewed, open access journal, publishing all aspects of clinica and experimental rheumatology in the clinic and laboratory including the following topics: Pathology, pathophysiology of rheumatologica diseases; Investigation, treatment and management of rheumatological diseases; Clinical trials and novel pharmacological approaches for the treatment of rheumatological disorders. The manuscript management system is completely online and includes a very quick and fair peerreview system, which is all easy to use. Visit http://www.dovepress.com/ testimonials.php to read real quotes from published authors.

Submit your manuscript here: http://www.dovepress.com/open-access-rheumatology-research-and-reviews-journal 